\title{
Identification of historical specimens and wildlife seizures originating from highly degraded sources of kangaroos and other macropods
}

\author{
P. B. S. Spencer $\cdot$ D. Schmidt $\cdot$ S. Hummel
}

Accepted: 25 August 2009/Published online: 5 November 2009

(C) Humana Press 2009

\begin{abstract}
Forensic investigations are an important area in the regulation of food mis-description, wildlife seizures and the international trade in wildlife and its products. An early, but important stage in dealing with many biological materials that are submitted for forensic scrutiny is species identification. We describe a method and new primers to amplify three small DNA fragments of the cytochrome $b$ region of the mitochondrial DNA that are suitable for marsupial species identification from degraded sources, such as wildlife seizures. They were designed as consensus sequences from a comparison of 21 marsupial species. The primers also contained sequences intended specifically not to amplify human DNA, thereby reducing the likelihood of amplifying contaminants. Examples of the utility of these primers are given using a range of conditions that may be applied using such an approach, including (1) fieldcollected sub-fossil bones, (2) an example of museum misidentification from a specimen collected in 1930 and (3) a skull collected from Bernier Island, in the harsh mid-west of Western Australia.
\end{abstract}

Keywords Wildlife forensic - Marsupial · Bone · Teeth $\cdot$ Sub-fossil

\footnotetext{
P. B. S. Spencer $(\bowtie)$

School of Biological Sciences and Biotechnology,

Wildlife Forensic Laboratory, Murdoch University, Perth,

Western Australia 6150, Australia

e-mail: P.Spencer@murdoch.edu.au

D. Schmidt $\cdot$ S. Hummel

Institute of Zoology and Anthropology, Historical Anthropology

and Human Ecology, Georg August-Universität Göttingen,

Bürgerstrasse 50, 37073 Göttingen, Germany
}

\section{Introduction}

In Australia, forensic investigations are important in a range of wildlife areas including the regulation of fraudulent description of food products, wildlife seizures and the international trade in wildlife and its products [1]. One such group, the kangaroos are internationally recognized iconic wildlife. The group belong to the superfamily Macropodoidea (or macropods), and contain about 45 living species in Australia [2]. There is currently no specific method or comparative database to identify DNA from highly degraded sources of kangaroo species in Australia. Modern molecular techniques have enabled the extraction and sequencing of DNA from old or museum specimens such as bone, teeth, feathers or skin [3-6]. Access to this degraded DNA provides an invaluable resource for wildlife protection, systematics and conservation research over a large time scale. Museum specimen sequences have already proved crucial to a number of wildlife genetic studies e.g. [5, 7-9]. It is estimated that the world's natural history museums hold in the order of 1.5 billion specimens [10] and these, from a genetic perspective, have hitherto been greatly under-utilised. It is also recognised that the world's mammals are declining rapidly [11]. The advantages of using museum specimens over fresh specimens are well recognised and include the possibility that fresh specimens may be costly to obtain due to the remoteness of habitat, the behaviour of the species or the fact that the species under investigation may exist in politically sensitive regions [10]. Museum collections may also contain specimens from species which are now extinct $[10,12]$. Use of museum specimens may therefore be both time and cost saving, and importantly, allow access to information which may no longer be obtainable from living systems. 
In Australia there are an increasing number of studies that have utilised old museum specimens for marsupial research e.g. [13, 14] but there remains little general information about this potentially powerful application to marsupial fauna. Future marsupial research may need to rely to a greater extent on museum specimens due to Australia's recognised small mammal decline, high extinction rates, habitat destruction and fragmentation [15] and difficulty in obtaining specimens [10]. For example in the case of endangered species persisting in fragmented habitats, an understanding of the historical changes (using museum or sub-fossil material) is crucial for conservation.

An important consideration in analysing ancient DNA (aDNA) sources is that the material is often highly degraded. For repeatability, the amplification of the targeted sequence information should be from primers that give a PCR product as short as possible (preferably $<200 \mathrm{bp}$ [6]). We applied this approach to our sequencing of the cytochrome $b$ (cyt $\mathrm{b}$ ) region of the mitochondrial genome for three marsupial specimens. Cytochrome $b$ is a well defined region with adequate variation to discriminate marsupial taxa e.g. $[8,16,17]$ and has been very widely used, and commonly is amplified by 'universal primers' $[18,19]$ or in the identification of forensic samples [20, 21]. Technical difficulties inherent to the analysis of small quantities of DNA generally tend to limit the efficiency of this approach. Two of the limitations with using these universal primers for museum specimens (particularly marsupials) are that the fragments are generally too large for successful amplification when the DNA is highly degraded and by virtue of the fact that they are 'universal', they have not been designed specifically for the taxa under investigation and may amplify non-target DNA.

In order to answer questions on sample identification of marsupial museum specimens and those sourced from degraded samples, we designed a set of primers to amplify three relatively small amplicons of the cytochrome $b$ gene in the marsupial mitochondrion. Using these primers, we demonstrated that it was possible to (1) obtain authentic amplicons from a range of macropod species, (2) obtain such DNA from different types of material (bone and teeth) and (3) identify and assign each specimen to a species.

\section{Materials and methods}

Samples and source material for degraded-source DNA analysis

A total of seven DNA extracts were isolated from different skeletal components (bone and teeth) from three specimens of marsupials described in Table 1. Each specimen represented a common situation found in our laboratory that has been encountered when dealing with marsupial questions involving degraded DNA, such as from wildlife seizures and international trade questions. These include:

1. sub-fossil Euro (Macropus robustus). This sample was collected as a crushed skull, which included the complete set of upper molar teeth (Sample identification Gö01; Table 1). The partial bleached skull was collected in the field at Mt. Keith Station, Western Australia. No other bones were found in the vicinity of the skull, suggesting that it had been exposed for a considerable period of time, although we do not have an exact period of exposure. This specimen was intended to represent a 'typical' field sample, where the specimen was obviously in a poor state of preservation and has been exposed to extreme ambient temperatures $\left(0-45^{\circ} \mathrm{C}\right.$; Meekathara weather station).

Table 1 Details of specimens, condition and DNA yield from marsupials

\begin{tabular}{|c|c|c|c|c|}
\hline Species & Specimen condition & Sample No. & $\begin{array}{l}\text { DNA conc } \\
(\mathrm{ng} / \mu \mathrm{l})\end{array}$ & $\begin{array}{l}\text { DNA yield } \\
\text { (ng/mg sample) }\end{array}$ \\
\hline \multirow[t]{4}{*}{ Macropus robustus ${ }^{\mathrm{a}}$} & \multirow{4}{*}{$\begin{array}{l}\text { Bleached skull (partial) collected at Mt. Keith Station, } \\
\text { W.A in 2001. No bones in vicinity of skull. Exposed } \\
\text { for }>6 \text { months }\end{array}$} & Gö01-1 (tooth) & 60 & 21 \\
\hline & & Gö01-2 (tooth) & 8 & 2 \\
\hline & & Gö01-3 (bone) & $<1$ & - \\
\hline & & Gö01-4 (tooth) & 12 & 1 \\
\hline Notomys & $\begin{array}{l}\text { Femur sampled from museum specimen labelled } \\
\text { Notomys alexis }\end{array}$ & & & \\
\hline$(\mathrm{M} 1461)^{\mathrm{b}}$ & $\begin{array}{l}\text { Suspect mis-labelled. Collected in 1930, } \\
\text { Canning stock Route, W.A. }\end{array}$ & Gö02-1 (bone) & 158 & 23 \\
\hline \multirow[t]{2}{*}{ Lagorchestes hirsutus $^{\mathrm{a}}$} & \multirow{2}{*}{$\begin{array}{l}\text { Partial bleached skull (crushed) collected } \\
\text { from Bernier Island, W.A. in } 1989\end{array}$} & Gö03-1 (tooth) & 12 & 1 \\
\hline & & Gö03-2 (bone) & 37 & 4 \\
\hline$(\mathrm{M} 47274)^{\mathrm{b}}$ & & & & \\
\hline
\end{tabular}

${ }^{a}$ Exposed to extreme humidity and ambient temperatures of $0-45^{\circ} \mathrm{C}$

b Western Australian museum accession number 
Duplicate DNA extractions were performed on samples of bone and tooth material (i.e. a total of four extractions were carried out on this specimen). Each extract was carried out separately (details given in Table 1).

2. mis-labelled museum specimen (a "Notomys"). A single DNA extraction was carried out on a small section $(0.34 \mathrm{~g})$ of the femur from a museum specimen labelled "Notomys alexis", collected in 1930 on the Canning Stock route (Western Australian Museum Accession No. M1461). We suspected that this specimen may have been mis-labelled, as the bone fragment was $92 \mathrm{~mm}$ long, only slightly shorter than the $95 \mathrm{~mm}$ head-body length of the spinifex hopping mouse it was supposedly from [2]. The sample appeared to be well preserved and in good condition.

3. Rufous Hare-wallaby or Mala (Lagorchestes hirsutus). Two DNA extractions were performed from bone $(0.45 \mathrm{~g})$ and tooth $(0.48 \mathrm{~g})$ material of a partially bleached and crushed skull which included the molar teeth (WA museum accession No. M47274) collected from Bernier Island, Western Australia in 1989. The age of the sample was unknown, but it appeared old and weathered, having been exposed to extreme ambient temperatures and periods of high humidity for an unknown length of time, similar to that described in the first specimen.

Preparation of bone and tooth samples (from Hummel 2003)

The outer surface $(\sim 0.5 \mathrm{~mm})$ of the bone and teeth samples were removed using a dentist grinding drill (Horico Diamond Instruments, Model EWL K10) to remove possible surface contaminants. A small section of each sample ( $\sim 0.5 \mathrm{~g}$ ) was cut out and then pulverised in a mixing mill (Retsch Type MM2). The sample was decalcified by mixing $0.5 \mathrm{~g}$ of the powdered bone with $1.0 \mathrm{ml}$ of $0.5 \mathrm{M}$ EDTA ( $\mathrm{pH} 8.3$ ) via constant rotation for 18-24 h at room temperature. Samples were then centrifuged for $5 \mathrm{~min}$ at $3,000 \mathrm{rpm}$ to pellet any remaining hard material. The supernatant was used for DNA extraction in an automated nucleic acid extractor (Gene Pure 341; Applied Biosystems) beginning with a Proteinase K (39 U/mg; lyophilised, Applied Biosystems) digestion step at $56^{\circ} \mathrm{C}$ for $1 \mathrm{~h}$, and then followed by a standard phenol and chloroform extraction.

At the final automated step, samples were mixed with $5 \mu \mathrm{l}$ silica particle solution (Glassmilk $^{\mathrm{TM}}$, QBiogene), resulting in the DNA binding to the glass milk in the presence of iso-propanol (3.3 $\mathrm{ml}$ of $100 \%$ solution) and sodium acetate $(100 \mu \mathrm{l}$ of $2.0 \mathrm{M} \mathrm{NaAc}$; $\mathrm{pH} 4.5$; Applied
Biosystems). The mixture was gently mixed for $10 \mathrm{~min}$, and the silica particles collected on a filtration membrane (Applied Biosystems). The filtration membranes containing the DNA/silica samples were manually removed from the automated extractor and washed with $80 \%$ ethanol then allowed to air dry. The eluted DNA/silica samples were re-suspended in $50 \mu \mathrm{l}$ of sterile water (Ampuwa $^{\mathrm{TM}}$, Fresenius).

The quantity and quality of the DNA extract was determined using a scanning photometer (Secomam, Jouan). In order to remove the silica particles prior to spectrophotometry, the extracts were vortexed and agitated at $56^{\circ} \mathrm{C}$ for $10 \mathrm{~min}$, then centrifuged for $10 \mathrm{~s}$ at $5,000 \mathrm{rpm}$ to pellet the glass milk. DNA extract was used to measure the absorbance from $\lambda 200$ to $400 \mathrm{~nm}$ with DNA quantity determined at $260 \mathrm{~nm}$. The distribution of the curve generated could be used to determine the quality of the extract, following the approach of Hummel [6]. The extracts were ranked as being low, medium or high quality extracts. Low quality had poor DNA yield and associated co-purification of extraneous material and high quality had high DNA yield with little co-purification of other material, such as proteins (Table 1).

\section{Samples and source material for non-ancient DNA} analysis

In the same laboratory as the ancient DNA extractions were performed, a control DNA extraction (from human cheek cells) was also carried out using a Chelex ${ }^{\mathrm{TM}}$ protocol [22]. This 'contamination control sample' was used in each PCR to investigate that the PCR-primers were not targeting human DNA (the most likely source of contamination; see below).

In a separate laboratory, DNA was extracted from a blood sample from the 21 marsupial species used in primer design using a standard salting out procedure [23] for use as reference samples.

\section{Primer design}

We trialled the commonly used 'universal' cytochrome $b$ primers [18, 24] on a range of ancient DNA extracts ( $n=7$ ) following the procedures in Alacs et al. [25]. The success of these trials was very low (see results section) and so to improve amplification, primers were specifically designed to amplify relatively small DNA products, suitable for highly degraded DNA sources [6].

A human mitochondrial sequence was aligned using the 'PrimerSelect' module of the Lasergene ${ }^{\mathrm{TM}}$ program (DNAStar Inc) with sequences from 21 marsupial taxa (12 are shown in Fig. 1), with the remaining nine taxa being the brush wallaby (Macropus irma), western grey 
size (bp) assimilis) and bridled nailtail wallaby (Onychogalea

ATGACTAACT TACGTAAAAC TCACCCACTA ATCAAAATCA TCAACCACTC 50 ATTTACTGTC CTACCTGCAC CATCAAACAT TTCAGCCTGA TGAAACTTTG 100 GCTCGCTACT AGGAGCCTGC CTAATCATCC AAATCCTCAC AGGCCTATTC 150 TTAGCCATAC ACTACACAGC AGACACCCTA ACAGCCTTCT CATCAGTTGC 200 CCATATCTGC CGAGACGTAA ACTACGGCTG ATTAATCCGC AATCTACACG 250 CCAACGGAGC ATCCATATTC TTTATATGCC TATTCCTCCA CGTAGGA 300 $\longrightarrow$ 2F con't GGCATCTACT ATGGTTCATA CCTCTATAAA GAAACATGAA ATATCGGAGT 350 AATCCTCCTA CTAACCGTCA TAGCAACAGC TTTCGTAGGC TATGTCCTAC 400 CATGAGGGCA AATATCATTT TGAGGGGCTA CCGTAATTAC CAACCTCCTA 450 TCCGCTATCC CCTACATCGg TACAACACTA GTAGAGTGAA TCTGAGGTGG 500 $3 \mathrm{~F}$ con't

ATTCTCCGTA GACAAAGCTA CTCTCACACG СTTTTTTGCC TTCCACTTTA 550

TCTTACCGTT TATTATTACA GCCTTAGTAC TAGTTCACCT CCTATTCCTA 600

CACGAAACAG GCTCCAACAA CCCATCAGGA ATCAACCCCG ACTCAGACAA 650 AATCCCATTC CATCCATACT ATACAATCAA AGACGCACTT GGCCTTATAC 700 TTATACTCCT TGTCCTACTC ACACTAGCAC TATTTTCACC TGACATACTA 750 GGTGACCCAG ACAACTTCTC TCCTGCCAAA CCCACTCAGC ACCCACCACA 800

Fig. 1 A schematic representation of 800 base-pair sequence of the mitochondrial cytochrome $b$ gene from the Eastern grey kangaroo (Macropus giganteus; GenBank accession number MGU87137 [26]), with the approximate size of fragments generated from the PCR using the three new primer pairs given above the sequence to which they refer

kangaroo (M. fuliginosus), quokka (Setonix brachyurus), rufous rat kangaroo (Aepyprymnus rufescens), red-legged pademelon (Thylogale stigmatica), spectacled hare-wallaby (Lagorchestes conspicillatus), rufous hare-wallaby (Lagorchestes hirsutus), allied rock wallaby (Petrogale fraenata).

Primers, and where appropriate partially degenerative primers, were designed in conserved regions. Wherever possible, care was taken to incorporate mis-priming at the $3^{\prime}$ end with the human sequence in at least one of the primer sequences (Fig. 1). This was done in order to prevent amplification of potential human DNA contaminants. In addition, pentamer free energy plots ( $\mathrm{kcal} / \mathrm{mol})$ were used to increase the theoretical binding ability, particularly at the $3^{\prime}$ end of the primers, as discussed by Hummel [6]. Three pairs of macropod primers were designed (named Macytb1, Macytb2 and Macytb3) and the products of these gave predicted fragment sizes of 164, 188 and $202 \mathrm{bp}$, respectively (primer sequences given in Table. 2 and products shown schematically in Fig. 1). The total of the three fragments encompass a large amount of the region amplified with the single pair of 'universal' primers, the only section not amplified was 17 base pairs between the first and second sets of primers, which corresponded to a highly conserved region in the Macropodidae.

We also designed the primers to amplify the three fragments in a multiplex PCR (with the six primers), giving three distinct products in a single reaction. As the target sequences were of different size they were able to be resolved adequately on agarose (4\%) gels (Fig. 2) to determine PCR success. For definitive species identification the three PCR fragments were sequenced.

Table 2 Primer sequences for the Macyt 3 sequences for 12 of 21 marsupial species used for the design of primers for the cytochrome $b$ region in marsupials (the Macyt1 and Macyt2 primer alignments are not shown, but the sequences are given at the bottom of the figure)

\begin{tabular}{|c|c|c|}
\hline \multirow[t]{2}{*}{ Reference / sequence taxa } & \multicolumn{2}{|c|}{ Marsupial cytochrome b No. 3 primer sequence (Macyt3) } \\
\hline & Forward (F) & Reverse (R) \\
\hline primer sequence & GTGGATTCTCCGTAGACAAAG & GTCTTTGATTGTATAGTAKGGATGG \\
\hline Eastern grey kangaroo & $\ldots \ldots \ldots \ldots \ldots$ & $\ldots \ldots \ldots \ldots \ldots \ldots$ \\
\hline Dibbler & ............... & A...A..C......... \\
\hline Common wombat & $\ldots \ldots \ldots \ldots \ldots \ldots$ & ...A.CG.......A.A. \\
\hline Brushtail Possum & .А. $\ldots \ldots \ldots \ldots \ldots$ & A...A..G.C.....G.. \\
\hline Antechinus minimus & .С.Т..T.GA....... & A....A.G.......... \\
\hline Wallaroo &.$G \ldots \ldots \ldots \ldots \ldots$ & A.....G..C.A.A..G. \\
\hline Koala & ............ & $\ldots$...G........ \\
\hline Numbat & .С.С.Т..А...Т... & ......G..C......G.. \\
\hline Red kangaroo & $\ldots \ldots \ldots \ldots \ldots \ldots$ & А......С.А..... \\
\hline Thylacine & .A........G.... & A.....G......... \\
\hline Long-tailed dunnart & .А.С.Т..А.Т.Т... & A...A.... . . . . . \\
\hline Tammar & $\ldots \ldots \ldots$ А. ...... & $\ldots \ldots \ldots \ldots \ldots \ldots \ldots \ldots$ \\
\hline Human & .А..С.А..А..... GTC & $\ldots \ldots \ldots \ldots \ldots \ldots \ldots$ \\
\hline cytochrome $b$ primer sequence Macyt1 & CTGCCTAATCATCCAAATCYT & GGCATATAAAGAATATGGATGCT \\
\hline cytochrome $b$ primer sequence Macyt2 & CGAGGCATCTACTATGGTTCATA & CACCTCAGATTCACTCTACTAGKGT \\
\hline
\end{tabular}

All primer sequences are given $5^{\prime}-3^{\prime}$ orientation 


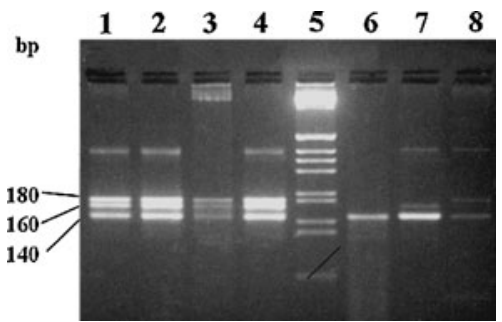

Fig. 2 Agarose gel electrophoresis showing discrimination of the three primer products. Lane 1-4 are samples Gö 01-1-Gö 01-4 (Table 1). Lane 5 is a molecular weight standard (reading from bottom to top are 75, 134, 154, 201, 220, 298, 344, 396 and 506/517 base pairs). Lane 6 shows a single small band of 142 bp from sample Gö03-1, lane 7 shows bands from the same sample showing products at 142 and 162 bp and in lane 8 sample Gö 03-2, showing products at 142 and $180 \mathrm{bp}$. These varying sized bands were generated by using combinations of the three primer sets

\section{PCR conditions}

All PCRs for the three new 'ancient' DNA primer pairs (for fragments Macytb1, 2 and 3; Table 2) were initially carried out in a multiplex PCR of a total volume of $50 \mu$ with $1 \mathrm{U}$ of AmpliTaqGold ${ }^{\mathrm{TM}}$ DNA polymerase (Applied Biosystems), approximately $100 \mathrm{ng}$ of template DNA (which included the silica suspension), $1.0 \mathrm{pmol}$ of each primer, $200 \mu \mathrm{M}$ dNTPs (solutions of dATP, dCTP, dGTP, dTTP; Sigma-Aldrich), $2 \mathrm{mM} \mathrm{MgCl}_{2}$, and $1 \times$ polymerase buffer II (100 mM Tris-HCl; pH 8.3, $500 \mathrm{mM} \mathrm{KCl)} \mathrm{supplied} \mathrm{by}$ the manufacturer. The reaction mix was overlayed with Mineral oil (Nujol ${ }^{\mathrm{TM}}$; Applied Biosystems), which helped to reduced aerosol contamination when opening tubes. After an initial $10 \mathrm{~min}$ denaturation step at $94^{\circ} \mathrm{C}$, the reaction tubes were exposed to 45 cycles of the following protocol: $1 \mathrm{~min}$ at $94^{\circ} \mathrm{C} ; 1 \mathrm{~min}$ at $50^{\circ} \mathrm{C} ; 1 \mathrm{~min}$ at $72^{\circ} \mathrm{C}$, with a final extension step of $30 \mathrm{~min}$ at $64^{\circ} \mathrm{C}$. These products were resolved on a $4 \%$ agarose gel (Fig. 2). All PCR amplification procedures included a negative and a non-marsupial (human DNA) control.

In a separate laboratory, the reference L. hirsutus sequence was obtained by PCR amplification using the cytochrome $b$ universal primer L14724 (5' GAAGCTTGATGAAAAACCATCGTTG $3^{\prime}$ [24]) and the new reverse primer Macytb3R (Fig. 2), with a final product size of $662 \mathrm{bp}$.

\section{Sequencing conditions}

The multiplex PCR products were sequenced directly using Taq cycle sequencing. This included a re-amplification reaction for each of the three products. The re-amplifications are carried out separately each using one primer of the respective primer pair as a sequencing primer. One microliter of the initial PCR was used as a template for the cycle sequencing using the Big-Dye terminator ${ }^{\mathrm{TM}}$ cycle sequencing chemistry (ABI PRISM, Applied Biosystems). The PCR conditions were: 30 s. $96^{\circ}, 15$ s. $50^{\circ} \mathrm{C}, 4 \mathrm{~min}$. $60^{\circ} \mathrm{C}, 30$ cycles.

The cycle sequencing products were electrophoresed using an automated DNA sequencer (model 310; ABI systems, Bethesda, Md.). Other reference sequences were obtained from GenBank (see Table 2), and these were from the complete mitochondrial sequences of the euroo (Macropus robustus [26]) and the eastern grey kangaroo (Macropus giganteus [26]). All sequences were edited and aligned by eye using SeqEd (Applied Biosystems, PerkinElmer).

\section{Results}

Samples and DNA extractions

Amplifiable DNA was successfully obtained from each bone and tooth sample (Fig. 2), although the quantity of the DNA varied widely, both with repeated extractions of a single specimen and among different specimens (Table 1). In general, bone material gave significantly greater yields of DNA than did tooth material $(F=410 ; d f=1$; $P=0.003)$.

\section{PCR primers and sequencing success}

\section{'Universal' primer trials}

PCR amplifications using the widely utilised 'universal primers' $[18,21,24]$ were attempted for the seven ancient DNA extracts (each sample run twice) and the control samples (negative and human). Only two PCR (662 bp) products were obtained and these were sequenced. One derived from the human DNA control, and the other from one of the Gö01-1 samples, which aligned using the BLAST search (http://www4.ncbi.nlm.nih.gov/BLAST/) with Macropus robustus (GenBank accession \# Y10524). Despite the relatively high DNA concentration $(160 \mu \mathrm{g} / \mu \mathrm{l}$, Table 1) the fact that only one amplification attempt (from repeated PCRs) of the Gö01-1 sample was successful suggests that very few larger intact fragments were present in the extract. This corresponds to the general experiences in ancient and degraded DNA analysis.

New 'degraded' DNA primer trials

All of the extracts were amplified using the three newly designed primer sets. Again this was carried out with duplicate PCRs and included the negative and the human controls. In contrast to the amplification attempts using the 
Table 3 Size of sequenced product and similarity to the most closely aligned GenBank sequence of the three new primers for amplifying the cytochrome $b$ region in three macropod samples (given in Table 1)

\begin{tabular}{llll}
\hline Species & Macropus robustus & "Notomys" & Lagorchestes hirsutus \\
\hline Sample number & Gö01 & Gö02 & Gö03 \\
Product length & & & 142 \\
Macytb1 primers & 144 & 141 & 190 \\
Macytb2 primers & 180 & $\mathrm{n} / \mathrm{a}$ & 162 \\
Macytb3 primers & 162 & 165 & AY099274 (Lagorchestes hirsutus) \\
GenBank alignment & Y10524 (Macropus robustus) & AY099273 (Lagorchestes hirsutus) & $98.6 \%$ \\
Sequence similarity & $99.9 \%$ & $99.9 \%$ & \\
\hline
\end{tabular}

Each sample was amplified and sequencing independently

a Sequence similarity to the most closely aligned data from GenBank

b No product was obtained, despite repeated attempts

"universal primers" of Kocher et al. [18] the human control sample remained blank with the newly designed primer set. Also in the negative control amplification products were not detectable.

From the sub-fossil Euro (Macropus robustus, samples Gö01-1-Gö01-4), the multiplex PCRs each resulted in three distinct-sized PCR products (Fig. 2), giving a total sequence length of $486 \mathrm{bp}$ (Table 3). The duplicate amplifications resulted in identical sequences, and showed $99.98 \%$ homology to M. robustus from Genbank (accession \# Y10524).

For the second specimen (the mis-labelled museum specimen, Gö02-1), only the first (cytb1) and third (cytb3) fragments could be amplified, despite repeated (four) amplification attempts. Nonetheless, for these two successfully amplified fragments, with a total sequence length of $306 \mathrm{bp}$, the resulting sequences showed $100 \%$ sequence identity to the rufous hare-wallaby (Lagorchestes hirsutus) reference sequence.

The third specimen, a partial skull from the Rufous harewallaby (Lagorchestes hirsutus, samples Gö03-1 and Gö032) yielded PCR fragments from each of the three amplified regions (total sequence length of $494 \mathrm{bp}$ ). However, due to an obviously stronger degree of DNA degradation the fragments were not always obtained simultaneously from each sample but at least the two larger fragments were only amplified randomly (Fig. 2). This phenomenon is commonly described as stochastic amplification. The analysis of the resultant sequences of a total length of $494 \mathrm{bp}$ confirmed the specimen to be near-identical $(99.98 \%)$ to the $L$. hirsutus reference sequence.

\section{Discussion}

Although the extraction and amplification of degraded DNA is well known, it remains underutilized and described in only a few reports investigating marsupial remains e.g.
$[8,13,14]$. In this study we set out to develop a marsupialspecific approach to the analysis of degraded DNA and have successfully amplified DNA from marsupials that had been preserved or found in a variety of different states of preservation. Specimen sources ranged from appropriately curated museum vouchers to material that had been found in the field. Being able to obtain DNA from a variety of sources are important because an enormous amount of marsupial material are accessible as sub-fossil specimens only, and many of the existing material derives from species that are now extinct.

We described the development and utilisation of a set of three primer pairs for the amplification of cytochrome $b$ PCR fragments suitable for amplifying degraded DNA from marsupial samples. The new primer set offers a number of advantages to more conventional primers in the approach to ancient and degraded DNA. Firstly, the simultaneously amplified PCR fragments are relatively short (164, 188 and $202 \mathrm{bp}$ ), and are therefore like the characteristics of degraded DNA. Secondly, the simultaneous amplification of different fragments in a multiplex approach saves valuable sample materials. Thirdly, the use of primers where the focus was on species-specificity, avoids the amplification of potentially present contaminants. The experiments showed that only a few mismatches at the $3^{\prime}$ ends of the primers are sufficient to discriminate against human DNA which is the most probable contaminant in ancient DNA analysis from field and museum specimens.

The importance of degraded DNA sources for investigating conservation questions with Australian marsupials will increase as more species experience decline. There are already a number of macropods with high conservation importance. To illustrate the use of this technology, there are four species of hare-wallabies of which all but one (L. conspicillatus) are either extinct ( $L$. leporides and $L$. asomatus) or endangered ( $L$. hirsutus). In mainland Australia, populations of the mala (L. hirsutus) persisted in 
the Great Sandy and Gibson Deserts until the 1950s. By 1960 only two small colonies of mainland populations of the mala remained in the Tanami Desert (about $500 \mathrm{~km}$ north-west of Alice Springs). One colony became extinct in late 1987, destroyed by a single fox. The second colony was wiped out by wildfire in 1991. The mala is now classified as endangered, and has been extinct on mainland Australia for over a decade [27]. The species now persists in a single fenced enclosure in central Australia, and on three offshore islands. It should now be possible to exploit the vast amounts of museum and sub-fossil material to investigate historical and conservation questions in these and many other macropod species. An analysis system that combines primers specific for marsupials, small target sizes, and a multiplex PCR amplification approach will clearly be in favour in future studies using marsupial degraded DNA.

\section{Keypoints}

1. Wildlife forensic investigations are important for enforcing legal areas such as 'truth in labelling' of food, wildlife seizures and in monitoring the international trade in wildlife and its products.

2. Species identification is an important area of interest in wildlife forensics cases.

3. We describe a method that amplifies three short DNA fragments of the cytochrome $b$ region of the mitochondrial DNA in a number of marsupial species.

4. They were designed as consensus sequences from 21 marsupial species. The primers also contained sequence intended to exclude human DNA, reducing the chance of amplifying contaminants.

5. The methods described in this manuscript offer a mechanism to generate data that may help define the past distribution of marsupials and place those distribution patterns in some context to climate regimes based on geological or paleontological studies.

Acknowledgments We are very grateful for the comments and improvements made to the original manuscript by the reviewers and editor. This study received financial support from the Australian Academy of Sciences, Department of Environment and Conservation and Murdoch University (SRF and Animal Research Institute).

\section{References}

1. Alacs E, Georges A. Wildlife across our borders: a review of the illegal trade in Australia. Aust J For Sci. 2008;40(2):147-60.

2. Van Dyck S, Strahan R. The mammals of Australia. Sydney: New Holland Publishers; 2008.

3. Herrmann B, Hummel S. Ancient DNA recovery and analysis of genetic material from paleontological archaeological, museum, medical and forensic specimens. Berlin: Springer; 1993.
4. Lassen C, Hummel S, Herrmann B. Comparison of DNA extraction and amplification from ancient human bone and mummified soft tissue. Internatl J Legal Med. 1994;107:152-5.

5. Rosenbaum HC, Egan MG, Clapham PJ, Brownell RL, Malik S, Brown MW, et al. Utility of North Atlantic right whale museum specimens for assessing changes in genetic diversity. Conserv Biol. 2000;14:1837-42.

6. Hummel S. Ancient DNA typing methods, strategies and applications. Berlin: Springer; 2003.

7. Janczewski DN, Yukhi N, Gilbert DA, Jefferson GT, O'Brien SJ. Molecular phylogenetic inference from saber-toothed cat fossils of Rancho La Brea. Proc Natl Acad Sci. 1992;89:9769-73.

8. Krajewski C, Driskell AC, Baverstock PR, Braun MJ. Phylogenetic relationships of the thylacine (Mammalia: Thylacinidae) among dasyuroid marsupials: evidence from cytochrome $b$ DNA sequences. Proc Roy Soc Lond Series B. 1992;250:19-27.

9. Wayne RK, Leonard JA, Cooper A. Full of sound and fury: the recent history of ancient DNA. Ann Rev Ecol Syst. 1999;30:457-77.

10. Thomas RH. Molecular ecology and evolution: approaches and applications. Berlin: Birkhauser Verlag; 1994.

11. Cardillo M, Mace GM, Gittleman JL, Jones KE, Bielby J, Purvis A. The predictability of extinction: biological and external correlates of decline in mammals. Proc Roy Soc Lond Series B. 2008;275:1441-8.

12. Cooper A. DNA from museum specimens. In: Herrmann B, Hummel S, editors. Ancient DNA. New York: Springer-Verlag; 1994. p. 149-65.

13. Taylor AC, Sherwin WB, Wayne RK. Genetic variation of microsatellite loci in a bottlenecked species- the northern hairynosed wombat Lasiorhinus krefftii. Mol Ecol. 1994;3:277-90.

14. Krajewski C, Buckley L, Westerman M. DNA phylogeny of the marsupial wolf resolved. Proc Roy Soc Lond Series B. 1997; 264:911-7.

15. Serena M. Reintroduction biology of Australian and New Zealand fauna. Chipping Norton: Beatty Surrey \& Sons; 1995.

16. Armstrong LA, Krajewski C, Westerman M. Phylogeny of the dasyurid marsupial genus Antechinus based on cytochrome b, 12S rRNA, and protamine P1 genes. J Mammal. 1998;79:1379-89.

17. Krajewski C, Painter J, Driskell AC, Buckley L, Westerman M. Molecular systematics of New Guinean Dasyurids. Sci New Guinea. 1993; 19:157-66.

18. Kocher TD, Thomas WK, Meyer SV, Edwards SV, Paabo S, Villablanca FX, et al. Dynamics of mtDNA evolution in animals: amplification and sequencing with conserved primers. Proc Natl Acad Sci. 1989;86:6196-200.

19. Teletchea F, Bernillon J, Duffraisse M, Laudet V, Hanni C. Molecular identification of vertebrate species by oligonucleotide microarray in food and forensic samples. J Appl Ecol. 2008; 45:967-75.

20. Branicki W, Kupiec T, Pawlowski R. Validation of cytochrome b sequence analysis as a method of species identification. J For Sci. 2003;48:1-5.

21. Verma SK, Singh L. Novel universal primers establish identity of an enormous number of animal species for forensic application. Mol Ecol Notes. 2003;3:28-31.

22. Walsh PS, Metzger DA, Higuchi R. Chelex 100 as a medium for simple extraction of DNA for PCR-based typing from forensic material. BioTechniques. 1991;10:506-13.

23. Miller SA, Dykes DD, Polesky HF. A simple salting out procedure for extracting DNA from human nucleated cells. Nuc Acids Res. 1988;16:1215.

24. Meyer A, Kocher TD, Basasibwaki D, Wilson AC. Monophyletic origin of Lake Victoria cichlid fishes suggested by mitochondrial DNA sequences. Nature. 1990;347:550-3.

25. Alacs E, Alpers DL, de Tores P, Dillon M, Spencer PBS. Identifying the presence of Quokkas (Setonix brachyurus) and other 
macropods using cytochrome $b$ analyses from faeces. Wildl Res. 2003;30:40-7.

26. Janke A, Xu X, Arnason U. The complete mitochondrial genome of the wallaroo (Macropus robustus) and the phylogenetic relationship among monotremata, marsupialia, and eutheria. Proc Natl Acad Sci. 1997;94:1276-81.
27. Maxwell S, Burbidge A, Morris K. The 1996 action plan for Australian marsupials and monotremes Australasian marsupial and monotreme specialist group. Canberra: IUCN Species survival Commission, Environment Australia; 1996. 